\title{
Facial motor evoked potential with paired transcranial magnetic stimulation: prognostic value following microvascular decompression for hemifacial spasm
}

\author{
Jae Sung Park, MD, ${ }^{1,3}$ Seunghoon Lee, MD, ${ }^{1}$ Sang-Ku Park, MS, ${ }^{2}$ Jeong-A Lee, PhD, ${ }^{1}$ and \\ Kwan Park, MD, PhD ${ }^{1}$
}

Departments of ${ }^{1}$ Neurosurgery and ${ }^{2}$ Neurology, Samsung Medical Center, Sungkyunkwan University School of Medicine, Seoul; and ${ }^{3}$ Department of Neurosurgery, Konkuk University School of Medicine, Chungju, South Korea

\begin{abstract}
OBJECTIVE Microvascular decompression (MVD) is widely considered the treatment of choice for hemifacial spasm (HFS), but not all patients immediately benefit from it. Numerous electrophysiological tests have been employed to monitor the integrity of the facial nerve prior to, during, and after MVD treatment. The authors sought to verify if facial motor evoked potential (FMEP) with paired transcranial magnetic stimulation (pTMS) can be utilized as a tool to predict prognosis following MVD for HFS.
\end{abstract}

METHODS FMEP using pTMS was performed preoperatively and postoperatively for $527 \mathrm{HFS}$ patients who underwent an MVD treatment. Various interstimuli intervals (ISIs), which included 2, 10, 20, 25, 30, 75, and $100 \mathrm{msec}$, were applied for each paired stimulation and pTMS(\%) was obtained. A graph of pTMS(\%) versus each ISI was drawn for every patient and its pattern was analyzed in accordance with patients' clinical outcomes.

RESULTS With ISIs of 75 and $100 \mathrm{msec}$, pTMS(\%) was physiologically further inhibited, whereas it was relatively facilitated under ISIs of 20,25, and 30 msec; loss of this specific pattern, that is, further inhibition-relative facilitation, indicated impaired integrity of the facial nerve. Those patients who immediately benefited from an MVD and experienced no relapse tended to show proper restoration of this further inhibition-relative facilitation pattern $(p=0.01)$. Greater resemblance between the physiological pattern of pTMS(\%) and postoperative pTMS(\%) was correlated to better outcome $(p=0.019)$.

CONCLUSIONS A simple linear graph of pTMS(\%) versus each ISI may be a helpful tool to predict prognosis for HFS following an MVD.

https://thejns.org/doi/abs/10.3171/2018.8.JNS18708

KEYWORDS hemifacial spasm; microvascular decompression; transcranial magnetic stimulation; paired pulse; functional neurosurgery

$\mathrm{N}$ EUROVASCULAR compression on the facial nerve has been widely accepted as the proper pathophysiology of hemifacial spasm (HFS), which is supported by a high success rate of microvascular decompression (MVD). ${ }^{2,10,22,33,44}$ The electrophysiological mechanism of HFS, however, has not been fully elucidated. Two distinct, yet not mutually exclusive, hypotheses have been proposed: hyperexcitability of the facial nucleus versus axonoaxonal ephaptic transmission between peripheral branches of the facial nerve. . $^{4,25,29}$ Several electrophysiological investigation methods, including blink reflex, lateral spread responses (LSRs), F-waves, etc., have demonstrated that ephaptic transmission between facial nerve fibers existed in HFS patients, but these findings do not exclude more fundamental mechanisms, i.e., hyperexcitability of the facial nucleus. ${ }^{22,27,29,42}$ Møller and Jannetta attributed LSRs to ephaptic transmission alone or in combination with hyperexcitability of the facial nucleus. ${ }^{23-25}$ Transcranial magnetic stimulation (TMS), which has been a tool for electrical stimulation on the cerebral cortex, spinal roots, and cranial nerves, can also be useful in evaluation of HFS. A group in Japan utilized a single-pulse TMS in

ABBREVIATIONS FMEP = facial motor evoked potential; HFS = hemifacial spasm; IFR = inhibited-facilitated ratio; ISI = interstimuli interval; LSR = lateral spread response; MEP = motor evoked potential; MVD = microvascular decompression; PPR = perioperative pTMS(\%) ratio; pTMS = paired transcranial magnetic stimulation; REZ = root entry zone; TMS = transcranial magnetic stimulation.

SUBMITTED March 14, 2018. ACCEPTED August 9, 2018

INCLUDE WHEN CITING Published online December 21, 2018; DOI: 10.3171/2018.8.JNS18708. 
evaluation of HFS and they inferred that hyperexcitability of the facial nucleus was the mechanism of HFS. ${ }^{15,20} \mathrm{We}$ hereby present results from our novel prospective study in which facial motor evoked potential (FMEP) using a paired TMS (pTMS) was performed in 527 HFS patients, prior to and after MVD surgeries.

\section{Methods}

A total of 637 consecutive HFS patients underwent an MVD at our institution between January 2012 and June 2014. Due to their past history of preoperative facial palsy or Botox injection, 31 and 15 patients, respectively, were excluded. Fifty-six patients who had developed postoperative facial palsy, no matter how temporary it was, were also excluded from any paired comparisons between preand postoperative assessment. With the exclusion of 8 more patients whose clinical results were unclear, a total of 527 patients were included in the postoperative analysis and they all went through an FMEP with pTMS test, both prior to and after the MVDs. The postoperative FMEP was performed approximately 3 weeks after the MVD.

There were $372(70.6 \%)$ female and 155 (29.4\%) male patients. Patient age ranged from 18 to 80 years and the mean age was 51.5 years. Two hundred fifty-three patients presented with right-sided spasm and 274 with left-sided spasm. The mean duration of symptoms was 5.2 years. Pure tone audiometry and speech discrimination tests were preoperatively performed in all patients. The mean follow-up period was 38.6 (24-54) months and all questionnaires concerning postoperative outcomes were administered and recorded by one nurse practitioner (J.L.) in order to minimize interinvestigator bias.

All MVDs were performed by a single surgeon (K.P.). The routine retromastoid suboccipital approach was employed, which was followed by opening of the dura mater and gentle retraction on the cerebellar tonsil. Upon inspection of the compressing vessels on the root entry zone (REZ) of the facial-vestibular and cochlear nerve complex, decompression commenced. Several pieces of Teflon sponge ball were inserted between the compressing vessels and the REZ, during which the greatest care was taken not to touch the REZ. What needed to be manipulated to complete the decompression was limited to compressing vessels along with the arachnoid trabeculae and perforating arteries. Throughout the surgery, between the initiation of general anesthesia and completion of stitches on the dura, brainstem auditory evoked potential and facial electromyography (EMG) were performed. The experimental protocol and informed consent were approved by the Institutional Review Board, and all subjects gave informed consent.

\section{FMEP With pTMS}

FMEP with pTMS was performed using a commercially available 70-mm figure-8 coil and 2 Magstim 200 stimulators (Magstim Co.) connected by a Bistim module. Relaxation of examinees was crucial for accurate results. TMS was not initiated until the examinee's whole body, not to mention the face, was fully relaxed in a comfortable reclining chair. Surface electrodes were applied for recording. The active electrode was placed $2 \mathrm{~cm}$ below the lower lip and $2 \mathrm{~cm}$ lateral to the midline, whereas the reference electrode was positioned inferior to the mouth angle. For stimulation, the center of the figure- 8 coil was positioned over the ipsilateral mastoid process retroauricularly, and then a more optimal site for each individual was determined as it was able to yield the maximal amplitude of MEP. The motor threshold (MT) was defined as the lowest intensity that was adequate to induce an MEP higher than $50 \mu \mathrm{V}$ during at least 5 successive trials. The single MEP was measured following a stimulus with supra-threshold (150\% of MT) intensity.

Two consecutive stimuli constituted a paired TMS: the conditioning stimulus (CS) and the test stimulus (TS). The former was set to $80 \%$ of MT, while the latter was administered using $150 \%$ of MT. The applied interstimuli intervals (ISIs) between CS and TS included 2, 10, 20, 25, 30,75 , and $100 \mathrm{msec}$. MEP following a pair of stimuli was obtained so that a pTMS(\%) value consistent with each ISI was calculated as $\mathrm{pTMS}(\%)=(\mathrm{MEP}$ after a paired stimulation/single MEP) $\times 100$.

The average of 5 consecutive pTMS(\%) values was used for the statistical analysis and was obtained for each ISI. A line graph with an $\mathrm{x}$-axis of 7 different ISIs and a $\mathrm{y}$-axis of pTMS(\%) was drawn for each patient (Figs. 1-3).

\section{Statistical Analysis}

The data processing was carried out using commercially available software (IBM SPSS Statistics, version 24). The Kruskal-Wallis one-way ANOVA test was utilized to compare data from FMEP with pTMS in relation to patient clinical outcomes. A linear-by-linear association test was employed when analyzing cross tables between groups.

\section{Results}

In accordance with their clinical outcomes, all patients were categorized into 4 groups, grade I, II, III, or IV (Table 1). The grade I group included those patients who became asymptomatic immediately after an MVD, then stayed spasm free. The grade II group consisted of patients whose symptoms persisted more than a month after an MVD but eventually disappeared in the long term. Successful groups, i.e., grades I and II, accounted for nearly $90 \%$ of the study patients ( $71.3 \%$ and $18.6 \%$, respectively). Patients with unsatisfactory postoperative outcomes fell into the grade III or IV groups. Patients whose MVD resulted in an immediate improvement that was followed by a long-term relapse were considered grade III, whereas those who had no or little benefit from the MVD were categorized into the grade IV group. As mentioned above, 8 patients $(1.5 \%)$ were excluded from the postoperative analysis because their clinical outcomes were too variable to fit into one of the 4 groups.

\section{Decrease of pTMS(\%) in Postoperative Versus Preoperative FMEP With pTMS}

The mean of the postoperative pTMS(\%) was $35.4 \%$ $( \pm 12.37 \%)$ and it was substantially lower than the preoperative value, which was $43.0 \%( \pm 8.64 \%)(\mathrm{p}=0.000)$. 


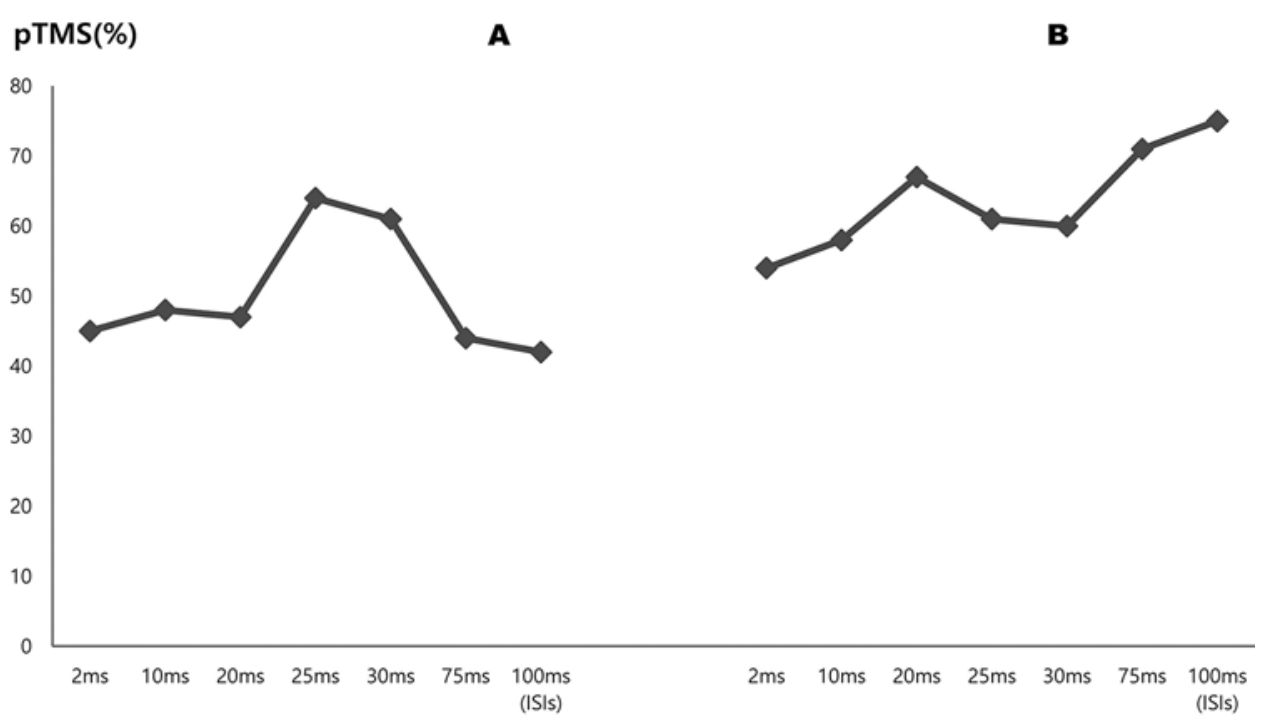

FIG. 1. Comparison of preoperative pTMS(\%) of a sample patient with 7 different ISIs shown on the x-axis. A: Asymptomatic side. B: Symptomatic (spasm) side.

The postoperative decrease of the mean pTMS $(\%)$ was noted in 418 (79.4\%) of 527 HFS patients. To verify the relationship between the extent of decrease in pTMS $(\%)$ and the postoperative clinical outcome, the perioperative pTMS(\%) ratio (PPR), the ratio of the postoperative to the preoperative $\mathrm{pTMS}(\%)$, was calculated as PPR = mean of postoperative $\mathrm{pTMS}(\%) /$ mean of preoperative $\mathrm{pTMS}(\%)$.

A lower PPR indicated that pTMS $(\%)$ had decreased more after the surgery. PPRs of the grade I and II groups were $0.82( \pm 0.37)$ and $0.85( \pm 0.41)$, whereas those of the grade III and IV groups were $1.00( \pm 0.59)$ and $0.94( \pm$ $0.33)$ (Fig. 4). The PPRs of the groups with better outcomes seemed lower than those of the groups with poorer outcomes. Statistical analysis using the Kruskal-Wallis test, however, failed to prove a direct correlation between PPR and clinical outcomes $(\mathrm{p}=0.063)$.

\section{Facilitation and Inhibition of FMEP With pTMS in Accordance With Various ISIs: Preoperative Analysis}

When an FMEP with pTMS test was applied to an asymptomatic (i.e., physiological) facial nerve, the pTMS(\%) appeared to be higher when the applied ISIs were 20,25 , and $30 \mathrm{msec}$ than when the ISIs were 75 and 100 msec. In other words, the pTMS(\%) seemed to be "relatively facilitated" under ISIs between 20 and $30 \mathrm{msec}$, whereas it appeared "further inhibited" under ISIs of 75 and 100 msec. An example of a line graph of pTMS(\%) with ISIs of $2,10,20,25,30,75$, and $100 \mathrm{msec}$ on the asymptomatic side is shown in Fig. 1A. Physiological further inhibition of pTMS(\%) occurred when ISIs were 75 and $100 \mathrm{msec}$, so that the graph resembled a "fedora." pTMS graphs for 511 of 527 (97.0\%) patients showed the

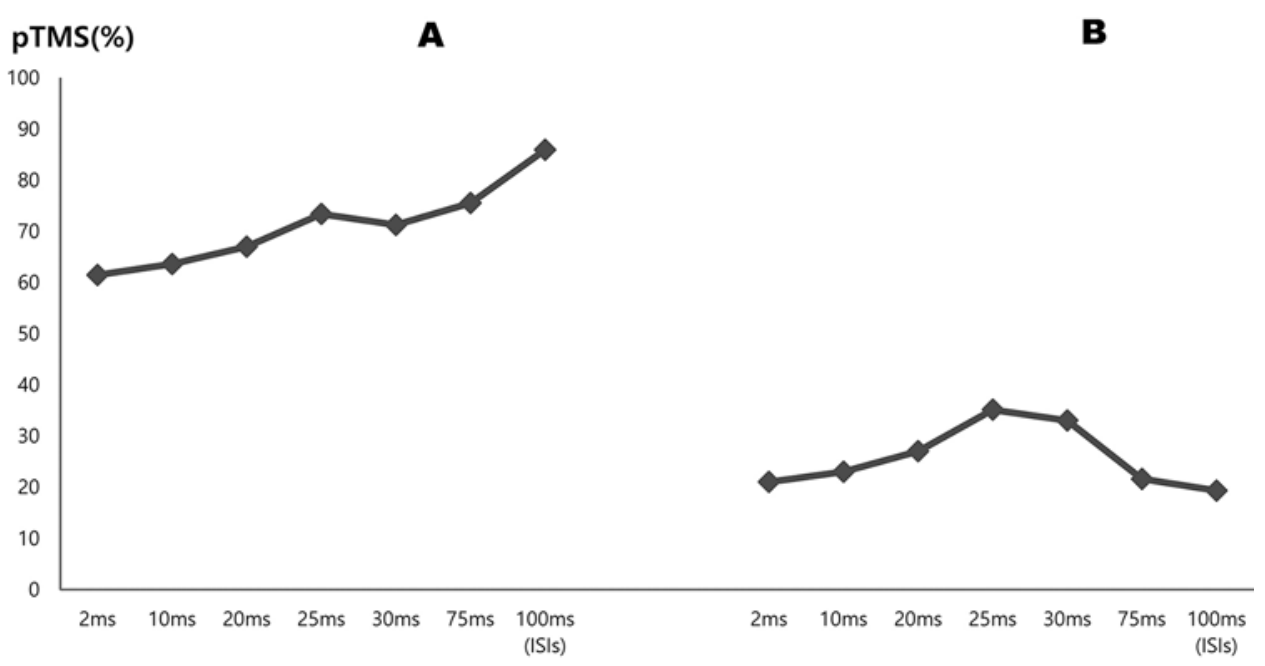

FIG. 2. Comparison of preoperative and postoperative pTMS(\%) for a successfully treated patient. A: Preoperative pTMS(\%) showing no physiological inhibition at ISIs of 75 and $100 \mathrm{msec}$. B: Postoperative pTMS(\%) showing restoration of physiological inhibition: a "fedora" shape. 


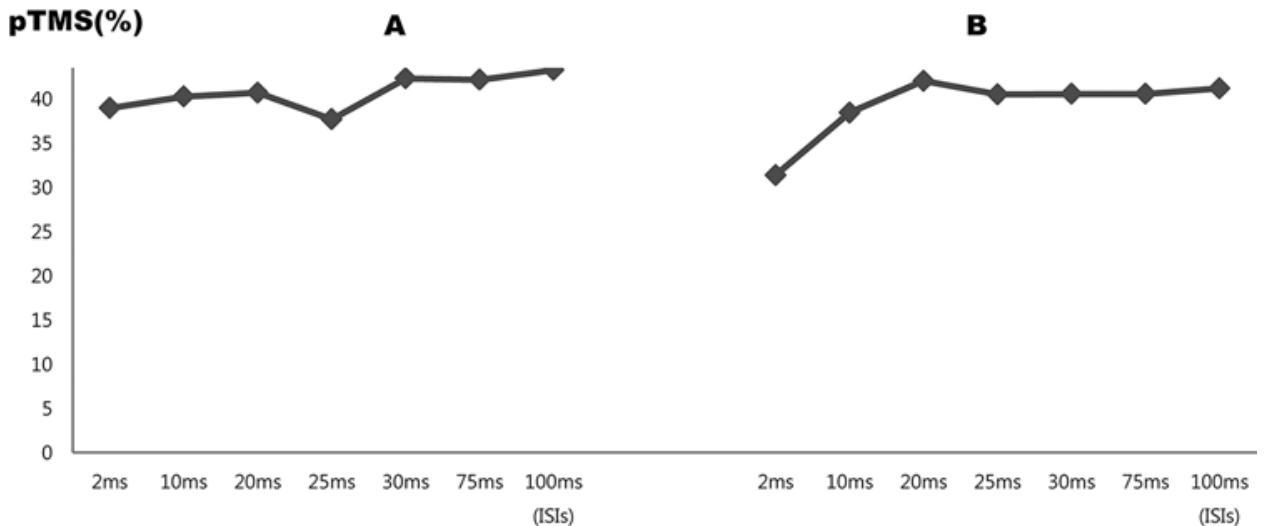

FIG. 3. Comparison of preoperative and postoperative pTMS(\%) for a patient whose outcome was unsatisfactory. A: Preoperative pTMS(\%) showing no physiological inhibition at ISIs of 75 and $100 \mathrm{msec}$. B: Postoperative pTMS(\%) also showing no physiological inhibition.

typical further inhibition when the ISI was 75 or $100 \mathrm{msec}$ on their asymptomatic side. On the other hand, the inhibition of pTMS(\%) under ISIs of 75 and 100 msec disappeared when an FMEP with pTMS test was used on the symptomatic facial nerve (Fig. 1B). The graph no longer looked like a fedora since the pTMS(\%) did not drop when ISIs were 75 and $100 \mathrm{msec}$. pTMS(\%) graphs for 502 of $527(95.2 \%)$ HFS patients did not show physiological "further inhibition" on their symptomatic sides.

\section{Facilitation and Inhibition of FMEP With pTMS in Accordance With Various ISIs: Postoperative Analysis}

For postoperative FMEP with pTMS testing, the typical graph for successfully treated patients showed the restoration of physiological inhibition under ISIs of 75 and 100 msec, with a shape resembling a fedora (Fig. 2B). Graphs for those patients who did not benefit from the MVD did not show the fedora pattern, because the physiological inhibition of pTMS under ISIs of 75 and $100 \mathrm{msec}$ was not sufficiently restored (Fig. 3B).

Whether or not a patient's pTMS(\%) graph restored the physiological further inhibition was determined by calculation of the inhibited-facilitated pTMS(\%) ratio (inhibited-facilitated ratio [IFR]) with the following formula: IFR $=$ mean $\mathrm{pTMS}(\%)$ under ISIs of 75 and $100 \mathrm{msec} / \mathrm{mean}$ pTMS(\%) under ISIs of 20, 25, and $30 \mathrm{msec}$.

IFR $<1$ would indicate some restoration of physiological inhibition of pTMS(\%) under ISIs of 75 and $100 \mathrm{msec}$.

TABLE 1. Categorization according to patient postoperative outcomes

\begin{tabular}{llc}
\hline Grade & Categorization According to Clinical Outcomes & No. of Pts (\%) \\
\hline I & Immediate improvement, no relapse & $376(71.3 \%)$ \\
\hline II & Delayed improvement, no relapse & $98(18.6 \%)$ \\
\hline III & $\begin{array}{c}\text { Immediate improvement followed by persistent } \\
\text { relapse }\end{array}$ & $19(3.6 \%)$ \\
\hline IV & No or little improvement & $34(6.5 \%)$ \\
\hline Total & & $527(100 \%)$ \\
\hline
\end{tabular}

Pts $=$ patients
The IFR of the grade I group was $0.78( \pm 0.09)$ and those of the grade II, III, and IV groups were $0.81( \pm 0.10), 0.79$ $( \pm 0.09)$, and $0.82( \pm 0.08)$, respectively (Fig. 5). IFR of the grade I group was significantly lower than those of the other 3 groups $(\mathrm{p}=0.01$, Kruskal-Wallis one-way ANOVA). Given that means of IFR from all 4 groups are closely distributed around 0.8 , IFR $<0.8$ was adopted for the meaningful restoration of physiological inhibition.

Based on IFR and PPR, all patients were categorized into 3 groups, A, B, and C. Group A included patients with ideal graphs: IFR $<0.8$ as well as PPR $<0.8$. Group $\mathrm{C}$ included those whose graph satisfied neither criterion, while group B consisted of the remaining patients whose graph fit in only one of the two criteria. Cutoff values were determined according to a receiver operating characteristic (ROC) curve that showed the sensitivity and specificity of IFR and PPR. IFR of 0.8 yielded $78 \%$ sensitivity and $50 \%$ specificity; their combined value was the maximum. PPR of 0.8 resulted in 50\% specificity and $50 \%$ sensitivity. As mentioned earlier, PPR by itself was unable to differentiate a good outcome from a bad one. However, when PPR was combined with IFR to categorize graph patterns (group $\mathrm{A}, \mathrm{B}$, and $\mathrm{C}$ ), the graph patterns were proven to correlate with the clinical outcomes $(p=0.019$, Table 2$)$.

\section{Discussion \\ Introduction of TMS}

The current style of TMS was first introduced by Anthony Barker in 1985. ${ }^{1}$ TMS was developed based on the electromagnetic theory. Rapid alteration of magnetic pulses results in a secondary ionic current in the brain, which leads to depolarization of neurons. Stimulation would take place where the spatial derivative was at a maximum. ${ }^{14}$ One of the major advantages of TMS is its noninvasiveness; no procedure to insert an intracortical probe is required and magnetic stimulation via the figure- 8 coil seldom causes any discomfort to examinees. On account of the ease of use, various applications of TMS have been attempted for many neurological diseases such as multiple sclerosis, stroke, brain injury, spinal cord injuries, amyotrophic lateral sclerosis, etc.,14,21,32,38 Paired-pulse TMS is one application of TMS using inhibiting and facilitating 


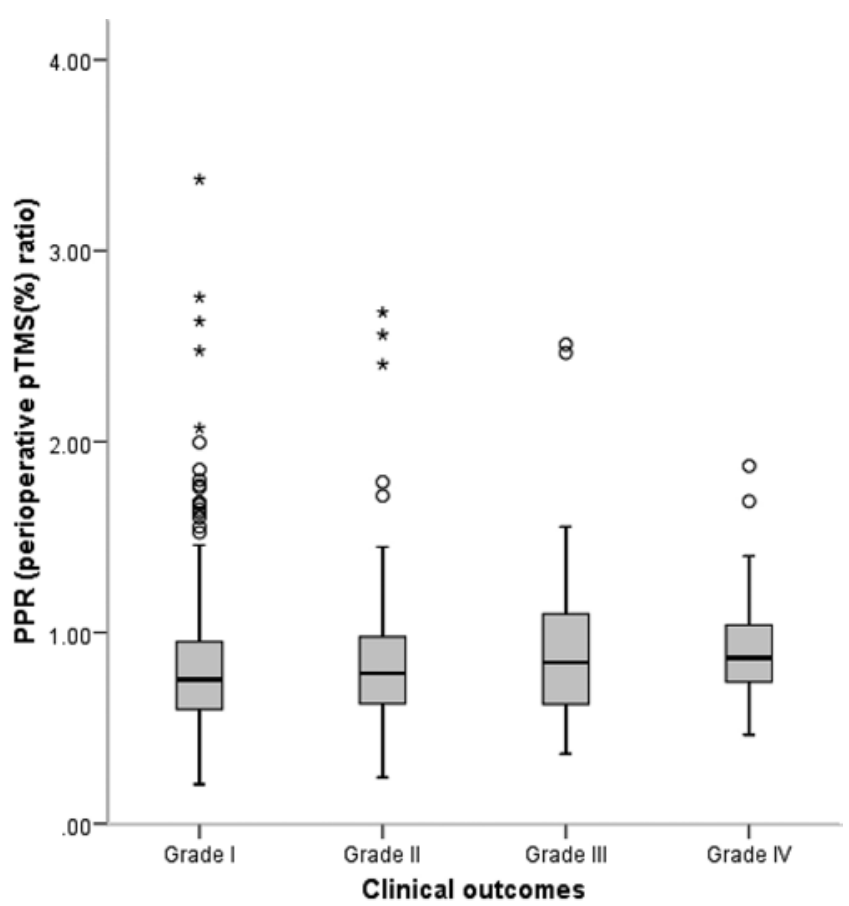

FIG. 4. A box plot representation of the PPR among 4 groups based on clinical outcomes ( $p=0.063$, Kruskal-Wallis one-way ANOVA).

interactions in the cortex. Depending on different ISIs, the MEP may be either inhibited or facilitated by TMS. TMS applied near the cerebral cortex using an ISI of 1-4 msec is reported to cause inhibition of MEP (commonly $20 \%-40 \%$ ), whereas an ISI of 7-20 msec tends to generate facilitation $(120 \%-300 \%)$ of the test MEP. ${ }^{14,18,34,45}$ The location of stimulation in our series was the retroauricular area, which differed from the location described in the previous literature, i.e., the cranial vault near the cerebral cortex. On account of that, FMEP with pTMS in our series resulted in only inhibition regardless of ISIs ranging from 2 to $100 \mathrm{msec}$, although the extent of inhibition varied depending on ISIs.

The phenomenon of inhibition or facilitation of neural activities after a paired TMS is considered to occur mainly via intercortical interneurons. ${ }^{30}$ In previous studies involving TMS, the method was tested on patients with movement disorders, postinfarction palsy, psychiatric disorders, etc., and yet the treatments described did not necessarily include pathways to and from the brainstem. Until now, the existence of interneurons in the human brainstem has not been universally accepted, although it has been well documented in rats, guinea pigs, rabbits, etc. ${ }^{3,16,36} \mathrm{On}$ the other hand, the literature reports the existence of direct projections in human brain, from the cerebral cortex to the facial motor nucleus, hypoglossal nucleus, nucleus ambiguous, and trigeminal motor nucleus, which could explain the connection between the intercortical interneurons and these nuclei. ${ }^{19,35}$ It still remains to be elucidated whether this inhibition-facilitation pattern is derived from hypothetical interneurons in the human brainstem or intercortical interneurons that project to the brainstem. Although our current study was focused on obtaining the MEP from the facial muscles, it might be feasible to collect signals

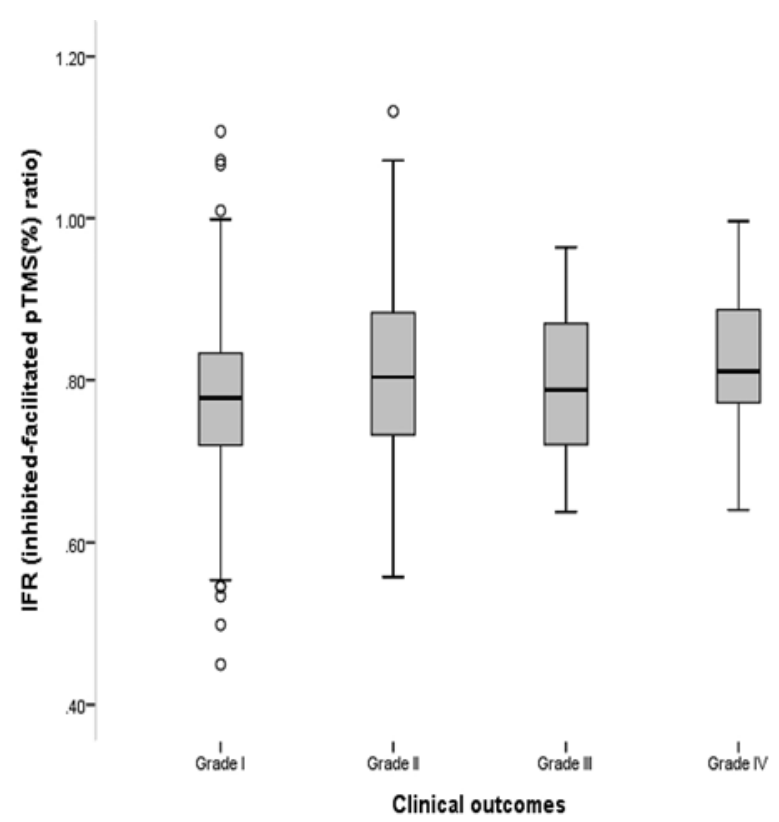

FIG. 5. A box plot representation of the IFR among 4 groups based on clinical outcomes ( $p=0.01$, Kruskal-Wallis one-way ANOVA).

from other nuclei if a different protocol was applied. We believe that in the future more studies involving neuroimaging and cytoarchitectonics may elucidate the precise mechanism of FMEP with pTMS.

\section{Employment of Facial MEP With pTMS Versus LSR}

Not every HFS patient who undergoes a successful MVD automatically experiences an immediate cure. As our previous studies suggested, the improving pattern of HFS following an MVD can vary from one individual to another; some eventually benefit from the surgery only after several months and some suffer a relapse. ${ }^{31}$ These relatively unpredictable improvement patterns have been a conundrum even for very experienced surgeons. Since Møller and Jannetta suggested in 1986 that intraoperative disappearance of LSR was correlated with clinical outcomes,${ }^{26}$ a number of authors have employed LSR as a prognostic determinant. Regarding the prognostic value of

TABLE 2. Association between graph patterns and clinical outcomes*

\begin{tabular}{|c|c|c|c|c|}
\hline \multirow[b]{2}{*}{ Clinical Outcome } & \multicolumn{3}{|c|}{ Graph Pattern } & \multirow[b]{2}{*}{ Total } \\
\hline & Group A† & Group B $\ddagger$ & Group C§ & \\
\hline Grade I & 153 & 69 & 154 & 376 \\
\hline Grade II & 27 & 17 & 54 & 98 \\
\hline Grade III & 4 & 6 & 9 & 19 \\
\hline Grade IV & 9 & 6 & 19 & 34 \\
\hline Total $(n=527)$ & 193 & 98 & 236 & 527 \\
\hline \multicolumn{5}{|c|}{$\begin{array}{l}{ }^{*} \text { Linear-by-linear association }(p=0.019) \text {. } \\
\dagger I F R<0.8 \text { and } P P R<0.8 \text {. } \\
\ddagger I F R<0.8 \text { and } P P R \geq 0.8 \text { or IFR } \geq 0.8 \text { and } P P R<0.8 \text {. } \\
\S I F R \geq 0.8 \text { and } P P R \geq 0.8 \text {. }\end{array}$} \\
\hline
\end{tabular}


LSR, however, no universal consensus has been reached. A meta-analysis concerning this matter deserves attention; based on 1301 cases available for meta-analysis by von Eckardstein et al., ${ }^{37}$ the authors concluded that disappearance of LSR during the MVD could predict clinical resolution of up to $90 \% .^{6,8,9,11,13,17,28,43}$ Persistence of LSR, however, does not necessarily predict a poor outcome. The authors insisted that LSR could be a useful tool to predict clinical outcomes, but it was not without limitations.

Our own previous reports also advocated the usefulness of LSR as a prognostic factor. ${ }^{12,17}$ Upon our more thorough observation, however, measurement of intraoperative LSR can be relatively subjective and the intraoperative change of LSR is not always consistent with postoperative LSR. In our current series, postoperatively persisting LSR was recorded in $83(35.2 \%)$ of 236 patients who were nearly symptom free in the month following MVD; 74 (89\%) of these 83 patients had already experienced disappearance of LSR during the surgery. This discrepancy would presumably be derived from the nature of LSR, i.e., its dependency on peripheral stimulation yielding a peripheral response. LSR is generated by the application of stimulation on a branch of the facial nerve and recorded from the facial musculature innervated by a different branch. ${ }^{39}$ One could assume that this relatively long pathway between the stimulation and response could be affected by factors that are not directly related to HFS itself. We attribute the inconsistency of LSR between intraoperative and postoperative measurement to this relatively long pathway. Paired TMS, however, does not stimulate peripheral branches of the facial nerve, which allows a shorter pathway.

\section{Pragmatic Value of FMEP With pTMS: PPR and IFR}

PPR [the perioperative pTMS(\%) ratio] represents how much the mean pTMS(\%) has decreased after the MVD regardless of various ISIs. IFR (the inhibited-facilitated ratio) symbolizes how much the physiological "further inhibition" under ISIs of 75 and $100 \mathrm{msec}$ was restored after the MVD. Lower IFR means better restoration of physiological inhibition, and a desirable postoperative pTMS(\%) graph would look like a fedora. Our results demonstrate that PPR $<0.8$ and IFR $<0.8$ indicate a favorable long-term prognosis $(p=0.019)$. Moreover, lower IFR per se dictates better prognosis $(\mathrm{p}=0.01)$. It would be advisable to draw a simple line graph of pTMS $(\%)$ for each patient prior to and after an MVD; if the postoperative graph is significantly lower than the preoperative one and it resembles a fedora, a better long-term prognosis can be anticipated. Even when a patient still suffers from residual spasms, if his or her pTMS $(\%)$ graph fits in an "ideal” fedora shape, a hasty decision for reoperation should be reconsidered.

\section{pTMS for Better Understanding of HFS}

The literature suggests that interneurons are attributable to the phenomenon of inhibition or facilitation according to various ISIs, when transcortical stimulation is presented in a paired fashion..$^{20,38,39}$ The fact that our results clearly demonstrated the inhibition-facilitation pattern may demonstrate the involvement of interneurons in the pathway, which, in turn, would advocate the hypothesis of hyperexcitability of the facial motor nucleus. We would not deny the existence of ephaptic transmission, and yet, we believe that hyperexcitability of the facial nucleus should be the proper basis for decompression. This is another reason that the greatest care must be taken to manipulate neither the distal facial nerve nor its REZ, which might account for our relatively high success rate $(89.9 \%)$ of MVD for HFS compared to the generally reported rate of $85.1 \%{ }^{41}$ Wilkinson and Kaufmann insisted that their intraoperative FMEP using corkscrew electrodes for a single stimulation on the facial nucleus could favor the "hyperexcitability of the facial nucleus" hypothesis. ${ }^{40}$ Fukuda et al. also suggested that intraoperative FMEP with single stimulation using corkscrew electrodes could be helpful in prediction of postoperative prognosis. ${ }^{5}$ These reports are consistent with our results, and yet our series affords its own advantage, in terms of not having to place redundant electrodes during surgery and demonstrating relatively high predictability for long-term prognosis. More detailed research on this FMEP with pTMS test will follow in the future, especially in regard to chronological analysis of repeated tests in patients with nonresponsive or aggravated spasms.

\section{Limitations of the Study}

In our protocol for employing facial MEP, prior history of Botox injection or facial palsy was considered to create a bias in obtaining results from TMS; therefore, 31 and 15 patients, respectively, who had undergone one of these treatments were excluded from the analysis. Likewise, 56 patients who had developed postoperative facial palsy were also removed from the study, because the objective of our current study was to compare data between preand postoperative assessments. However, the removal of the 56 patients may have contributed to a selection bias. We retrospectively ran additional statistical analyses comparing IFR among those who had developed postoperative facial palsy and those who had not. Postoperative IFR of the facial palsy group (0.782) seemed lower than that of the non-facial palsy group (0.801), but the difference was statistically insignificant $(\mathrm{p}=0.38)$. Preoperative IFR for those who had a history of facial palsy and developed postoperative facial palsy will be assessed and analyzed in the future.

The additional 8 subjects who were excluded due to their vague clinical courses also might have caused a bias. Their clinical courses had continued to fluctuate during the 2 years of the current study, which precluded us from defining the final clinical results even after the 2-year period. A chronological assessment for these patients with variable clinical status will follow in the future, when the repetitive FMEPs with pTMS are completed with a longer follow-up period.

\section{Conclusions}

FMEP with pTMS can be used as an adjunctive tool in diagnosis of HFS and it may offer a significant improvement in prediction of prognosis following an MVD. With more subsequent research on the FMEP with pTMS test, more profound understanding of HFS may be available in the future. 


\section{References}

1. Barker AT, Jalinous R, Freeston IL: Non-invasive magnetic stimulation of human motor cortex. Lancet 1:1106-1107, 1985

2. Barker FG II, Jannetta PJ, Bissonette DJ, Shields PT, Larkins MV, Jho HD: Microvascular decompression for hemifacial spasm. J Neurosurg 82:201-210, 1995

3. Chandler SH, Tal M: The effects of brain stem transections on the neuronal networks responsible for rhythmical jaw muscle activity in the guinea pig. J Neurosci 6:1831-1842, 1986

4. Ferguson JH: Hemifacial spasm and the facial nucleus. Ann Neurol 4:97-103, 1978

5. Fukuda M, Oishi M, Hiraishi T, Fujii Y: Facial nerve motorevoked potential monitoring during microvascular decompression for hemifacial spasm. J Neurol Neurosurg Psychiatry 81:519-523, 2010

6. Hatem J, Sindou M, Vial C: Intraoperative monitoring of facial EMG responses during microvascular decompression for hemifacial spasm. Prognostic value for long-term outcome: a study in a 33-patient series. Br J Neurosurg 15:496-499, 2001

7. Haug BA, Kukowski B: Latency and duration of the muscle silent period following transcranial magnetic stimulation in multiple sclerosis, cerebral ischemia, and other upper motoneuron lesions. Neurology 44:936-940, 1994

8. Huang BR, Chang CN, Hsu JC: Intraoperative electrophysiological monitoring in microvascular decompression for hemifacial spasm. J Clin Neurosci 16:209-213, 2009

9. Ishikawa M, Ohira T, Namiki J, Gotoh K, Takase M, Toya S: Electrophysiological investigation of hemifacial spasm: F-waves of the facial muscles. Acta Neurochir (Wien) 138:24-32, 1996

10. Jo KW, Kong DS, Park K: Microvascular decompression for hemifacial spasm: long-term outcome and prognostic factors, with emphasis on delayed cure. Neurosurg Rev 36:297-302, 2013

11. Joo WI, Lee KJ, Park HK, Chough CK, Rha HK: Prognostic value of intra-operative lateral spread response monitoring during microvascular decompression in patients with hemifacial spasm. J Clin Neurosci 15:1335-1339, 2008

12. Kim CH, Kong DS, Lee JA, Park K: The potential value of the disappearance of the lateral spread response during microvascular decompression for predicting the clinical outcome of hemifacial spasms: a prospective study. Neurosurgery 67:1581-1588, 2010

13. Kiya N, Bannur U, Yamauchi A, Yoshida K, Kato Y, Kanno $\mathrm{T}$ : Monitoring of facial evoked EMG for hemifacial spasm: a critical analysis of its prognostic value. Acta Neurochir (Wien) 143:365-368, 2001

14. Kobayashi M, Pascual-Leone A: Transcranial magnetic stimulation in neurology. Lancet Neurol 2:145-156, 2003

15. Kojima A, Ohira T, Takase M, Kawase T: Long-latency response to transcranial magnetic stimulation in patients with hemifacial spasm. Electroencephalogr Clin Neurophysiol 109:285-289, 1998

16. Kolta A, Westberg KG, Lund JP: Identification of brainstem interneurons projecting to the trigeminal motor nucleus and adjacent structures in the rabbit. J Chem Neuroanat 19:175195,2000

17. Kong DS, Park K, Shin BG, Lee JA, Eum DO: Prognostic value of the lateral spread response for intraoperative electromyography monitoring of the facial musculature during microvascular decompression for hemifacial spasm. J Neurosurg 106:384-387, 2007

18. Kujirai T, Caramia MD, Rothwell JC, Day BL, Thompson PD, Ferbert A, et al: Corticocortical inhibition in human motor cortex. J Physiol 471:501-519, 1993

19. Küypers HG: Corticobular connexions to the pons and lower brain-stem in man: an anatomical study. Brain 81:364-388, 1958

20. Laskawi R, Damenz W, Roggenkämper P, Schröder M, Brauneis J: [Magnetic stimulation in patients with facial hemispasm.] Laryngorhinootologie 69:237-241, 1990 (Ger)

21. Meyer BU, Röricht S, Gräfin von Einsiedel H, Kruggel F, Weindl A: Inhibitory and excitatory interhemispheric transfers between motor cortical areas in normal humans and patients with abnormalities of the corpus callosum. Brain 118:429-440, 1995

22. Møller AR: The cranial nerve vascular compression syndrome: II. A review of pathophysiology. Acta Neurochir (Wien) 113:24-30, 1991

23. Møller AR, Jannetta PJ: Hemifacial spasm: results of electrophysiologic recording during microvascular decompression operations. Neurology 35:969-974, 1985

24. Møller AR, Jannetta PJ: Microvascular decompression in hemifacial spasm: intraoperative electrophysiological observations. Neurosurgery 16:612-618, 1985

25. Møller AR, Jannetta PJ: On the origin of synkinesis in hemifacial spasm: results of intracranial recordings. J Neurosurg 61:569-576, 1984

26. Møller AR, Jannetta PJ: Physiological abnormalities in hemifacial spasm studied during microvascular decompression operations. Exp Neurol 93:584-600, 1986

27. Montero J, Junyent J, Calopa M, Povedano M, Valls-Sole J: Electrophysiological study of ephaptic axono-axonal responses in hemifacial spasm. Muscle Nerve 35:184-188, 2007

28. Neves DO, Lefaucheur JP, de Andrade DC, Hattou M, Ahdab $\mathrm{R}$, Ayache SS, et al: A reappraisal of the value of lateral spread response monitoring in the treatment of hemifacial spasm by microvascular decompression. J Neurol Neurosurg Psychiatry 80:1375-1380, 2009

29. Nielsen VK: Pathophysiology of hemifacial spasm: II. Lateral spread of the supraorbital nerve reflex. Neurology 34:427-431, 1984

30. Oliveri M, Rossini PM, Filippi MM, Traversa R, Cicinelli P, Palmieri MG, et al: Time-dependent activation of parietofrontal networks for directing attention to tactile space. A study with paired transcranial magnetic stimulation pulses in right-brain-damaged patients with extinction. Brain 123:1939-1947, 2000

31. Park JS, Kong DS, Lee JA, Park K: Chronologic analysis of symptomatic change following microvascular decompression for hemifacial spasm: value for predicting midterm outcome. Neurosurg Rev 31:413-419, 2008

32. Rossini PM, Rossi S: Clinical applications of motor evoked potentials. Electroencephalogr Clin Neurophysiol 106:180-194, 1998

33. Samii M, Günther T, Iaconetta G, Muehling M, Vorkapic P, Samii A: Microvascular decompression to treat hemifacial spasm: long-term results for a consecutive series of 143 patients. Neurosurgery 50:712-719, 2002

34. Schäfer M, Biesecker JC, Schulze-Bonhage A, Ferbert A: Transcranial magnetic double stimulation: influence of the intensity of the conditioning stimulus. Electroencephalogr Clin Neurophysiol 105:462-469, 1997

35. Sherwood CC: Comparative anatomy of the facial motor nucleus in mammals, with an analysis of neuron numbers in primates. Anat Rec A Discov Mol Cell Evol Biol 287:10671079,2005

36. Tanaka S, Kogo M, Chandler SH, Matsuya T: Localization of oral-motor rhythmogenic circuits in the isolated rat brainstem preparation. Brain Res 821:190-199, 1999

37. von Eckardstein K, Harper C, Castner M, Link M: The significance of intraoperative electromyographic "lateral spread" in predicting outcome of microvascular decompression for hemifacial spasm. J Neurol Surg B Skull Base 75:198-203, 2014 
38. Weber M, Eisen AA: Magnetic stimulation of the central and peripheral nervous systems. Muscle Nerve 25:160-175, 2002

39. Wilkinson MF, Kaufmann AM: Facial motor neuron excitability in hemifacial spasm: a facial MEP study. Can J Neurol Sci 41:239-245, 2014

40. Wilkinson MF, Kaufmann AM: Monitoring of facial muscle motor evoked potentials during microvascular decompression for hemifacial spasm: evidence of changes in motor neuron excitability. J Neurosurg 103:64-69, 2005

41. Xia L, Zhong J, Zhu J, Dou NN, Liu MX, Li ST: Delayed relief of hemifacial spasm after microvascular decompression. J Craniofac Surg 26:408-410, 2015

42. Yamashita S, Kawaguchi T, Fukuda M, Suzuki K, Watanabe M, Tanaka R, et al: Lateral spread response elicited by double stimulation in patients with hemifacial spasm. Muscle Nerve 25:845-849, 2002

43. Yamashita S, Kawaguchi T, Fukuda M, Watanabe M, Tanaka $\mathrm{R}$, Kameyama S: Abnormal muscle response monitoring during microvascular decompression for hemifacial spasm. Acta Neurochir (Wien) 147:933-938, 2005

44. Youman J: Neurological Surgery: A Comprehensive Reference Guide to the Diagnosis and Management of Neurosurgical Problems. Philadelphia: Saunders, 1996
45. Ziemann U, Rothwell JC, Ridding MC: Interaction between intracortical inhibition and facilitation in human motor cortex. J Physiol 496:873-881, 1996

\section{Disclosures}

The authors report no conflict of interest concerning the materials or methods used in this study or the findings specified in this paper.

\section{Author Contributions}

Conception and design: K Park. Acquisition of data: S Lee, SK Park, JA Lee. Analysis and interpretation of data: JS Park. Drafting the article: JS Park. Critically revising the article: JS Park.

Reviewed submitted version of manuscript: K Park, S Lee. Statistical analysis: JS Park. Administrative/technical/material support: SK Park, JA Lee. Study supervision: K Park.

\section{Correspondence}

Kwan Park: Samsung Medical Center, Sungkyunkwan University School of Medicine, Seoul, South Korea.kwanpark@skku.edu. 